Research Paper

\title{
PD-L1 is a Prognostic Biomarker in Resected NSCLC Patients with Moderate/high Smoking History and Elevated Serum SCCA Level
}

\author{
Lianjing Cao ${ }^{1,2,3^{*}}$, Xinyue Wang ${ }^{1,2,3^{*}}$, Shouying $\mathrm{Li}^{1,2,3}$, Qiongjie Zhi ${ }^{1,2,3}$, Yuqian Wang ${ }^{1,2,3}$, Liuchun Wang ${ }^{1,2,3}$, \\ Kai Li ${ }^{1,2,3}$, Richeng Jiang $1,2,3 \bowtie$ \\ 1. Tianjin Medical University Cancer Institute \& Hospital, National Clinical Research Center for Cancer; \\ 2. Key Laboratory of Cancer Prevention and Therapy, Tianjin; Tianjin's Clinical Research Center for Cancer; \\ 3. Department of Thoracic Oncology, Tianjin Lung Cancer Center, Tianjin Cancer Institute \& Hospital, Tianjin Medical University, Tianjin 300060, PR China. \\ *These authors contributed equally to this work and share first authorship. \\ $\triangle$ Corresponding author: Richeng Jiang, Department of Thoracic Oncology, Tianjin Lung Cancer Center, Tianjin Cancer Institute \& Hospital, Tianjin Medical \\ University, Tianjin 300060, China. Phone: 86-22-23340123-3200, Fax: 86-22-23537796. E-mail: jiangricheng@tjmuch.com \\ (C) Ivyspring International Publisher. This is an open access article distributed under the terms of the Creative Commons Attribution (CC BY-NC) license \\ (https://creativecommons.org/licenses/by-nc/4.0/). See http://ivyspring.com/terms for full terms and conditions.
}

Received: 2017.05.21; Accepted: 2017.08.07; Published: 2017.09.15

\begin{abstract}
Programmed cell death-1 (PD-1) -targeted immunotherapy has become a promising treatment paradigm for patients with advanced non-small cell lung cancer (NSCLC). Clinical responses to checkpoint inhibition therapy in NSCLC have been associated with programmed death-1 ligand 1 (PD-L1) expression. However, the association between the expression of PD-L1 and PD-L2 and the clinicopathological features and patient outcomes in NSCLC remain unclear. We retrospectively analyzed 364 patients (158 squamous cell carcinoma and 206 adenocarcinoma) who underwent complete resection between 2009 and 2012. Expression of PD-L1 and PD-L2 was determined by immunohistochemistry. Correlations between PD-L1/PD-L2 expression and the clinicopathological features and survival parameters were analyzed and prognostic factors were identified. PD-LI expression was significantly associated with moderate/heavy smoking history and serum squamous cell carcinoma antigen (SCCA) levels. Multivariate analysis showed patients with high PD-L1 expression had significantly shorter disease free survival (DFS, HR 1.411, P = 0.025) and overall survival $(O S, H R 1.659, P=0.004)$ than those with low PD-L1 expression at a $50 \%$ cutoff value. No significant association was found between PD-L2 expression and patient postoperative survival. Further stratification analysis revealed that in patients with moderate/heavy smoking history, elevated serum SCCA level, and squamous cell carcinoma, PD-LI expression was associated with significantly shorter DFS and OS. Therefore, PD-LI expression was correlated with moderate/heavy smoking history and elevated serum SCCA level in NSCLC patients, and was an independently poor predictor of survival.
\end{abstract}

Key words: PD-L1, PD-L2, prognostic biomarker, non-small cell lung cancer, squamous cell carcinoma antigen

\section{Introduction}

Despite striking improvement in diagnosis and treatment, lung cancer remains the leading cause of cancer-related death worldwide. Non-small cell lung cancer is predominantly comprised of adenocarcinomas and squamous cell carcinomas, accounting for approximately $85 \%$ of all lung cancer cases. Recent advancements in immunotherapy with anti-programmed death-1 (PD-1) monoclonal antibodies have led to a major paradigm shift in the treatment of NSCLC.

PD-1 is a member of the cluster of differentiation (CD) 28 family expressed on T cells, natural killer cells, monocytes and B cells. As an immune checkpoint receptor, it plays a crucial role in immune 
escape during tumor progression [1-4]. PD-1 ligands programmed death ligand 1 (PD-L1, CD274) and programmed death ligand 2 (PD-L2, CD273) are known to be negative immune regulators which interact with PD-1 to block cytotoxic T cell activity and facilitate tumor immune evasion [1, 5]. Immunotherapy with anti-PD-L1 or anti-PD-1 antibodies has successfully shown significant antitumor activities in various cancers including NSCLC [6-8]. As such, the durable clinical responses to nivolumab, pembrolizumab and atezolizumab have led to their rapid approval as second-line therapy for NSCLC [9]. However, overall response rates to these agents are still low, thus evaluation of the expression patterns of PD-L1/PD-L2 might provide valuable information to predict benefit to immunotherapies.

To date, the clinicopathological features related to PD-L1 and PD-L2 expression for patients with NSCLC remain controversial. Several studies have investigated the relation between PD-L1 expression and smoking history. Several groups detected higher PD-L1 expression in resected NSCLC patients who had a smoking history compared non/low-smokers [10-12], while another investigation found no relationship [13]. Furthermore, some studies have observed that squamous cell carcinoma patients exhibited significantly higher expression of PD-L1 [10, 11, 14] while others found it correlated with adenocarcinoma [12]. While serum tumor markers including carcinoembryonic antigen (CEA), neuron-specific enolase (NSE), cytokeratin-19 fragments (Cyfra21-1) and squamous cell carcinoma antigen (SCCA), are considered to be associated with lung cancer histology and to be predictive or prognostic in NSCLC, they have not been well investigated in relation to PD-L1/PD-L2 expression. In addition, there is not a consensus regarding the prognostic significance of PD-L1/PD-L2 expression in NSCLC.

In the present study, we investigated PD-L1 and PD-L2 expression in resected lung adenocarcinoma and squamous cell carcinoma and evaluated their association with clinicopathologic and molecular parameters, including epidermal growth factor receptor (EGFR) status, smoking history, age, sex, regional lymph node metastasis, clinical stage, tumor size as well as serum tumor markers. In addition, the prognostic value of PD-L1 and PD-L2 expression was examined.

\section{Materials and methods}

\section{Patients and specimens}

The retrospective cohort consisted of 364 patients (158 squamous cell carcinoma and 206 adenocarcinoma) who underwent surgical resection between 2009 and 2012 at the Tianjin Cancer Institute \& Hospital, Tianjin Medical University, Tianjin P.R. China. Pathologic diagnosis and clinicopathologic staging of the specimens were performed according to World Health Organization (WHO) histological classification and tumor-node-metastasis (TNM) classification system (AJCC, 1977). Patients who accepted any anti-tumor therapy (radiotherapy, chemotherapy or targeted therapy) before surgery, who died within two months after surgery or died of any other reason, were excluded for analysis. Tissue microarrays (TMA; $2 \mathrm{~mm}$ in diameter) were constructed using the most representative areas of the formalin-fixed paraffin embedded (FFPE) NSCLC tissues. In total, 158 patients with squamous cell carcinoma and 206 patients with adenocarcinoma were included and basic clinical parameters were recorded. Prior consent from all patients and approval from the Research Ethics Committee of Tianjin University were obtained for the use of clinical and pathological data.

\section{Measurement of serum CEA, NSE, SCCA and Cyfra21-1 levels and EGFR mutations}

All of the serum tumor marker levels were measured within two weeks before surgery using electrochemiluminescence immunoassay on a Roche Analytics E170 Immunology Analyzer (Roche Diagnostics, China). The cut-offs for serum marker levels were stipulated as follows according to manufacturer's recommendation: CEA $5.0 \mathrm{ng} / \mathrm{ml}$, NSE $15.2 \mathrm{ng} / \mathrm{ml}$, SCCA $1.5 \mathrm{ng} / \mathrm{ml}$, and Cyfra21-1 3.3 $\mathrm{ng} / \mathrm{ml}$. EGFR mutations, including EGFR exon 19 deletion (del19) and exon 21 Leu858Arg substitution (L858R), were identified by real-time PCR or DNA sequencing as previously described $[15,16]$. Other EGFR mutations were not tested for.

\section{Immunohistochemistry}

TMA blocks were sectioned at a thickness of $4 \mu \mathrm{m}$, and immunohistochemistry (IHC) was performed using the following antibodies: rabbit anti-PD-L1 $X \mathrm{P}^{\circledR} \mathrm{mAb}(1: 100$, EIL3N, Cell Signaling Technology, Danvers, MA, USA), mouse anti-PD-L2 mAb (1:200, clone 176611, R\&D system, Minneapolis, MN, USA). Briefly, sections were deparaffinized with xylene followed by an ethanol gradient. EDTA buffer was used for antigen unmasking, and sections were then incubated in 3\% hydrogen peroxide. After washing with Tris Buffered Saline with Tween ${ }^{\circledR} 20$ (TBST), slides were incubated overnight at $4^{\circ} \mathrm{C}$ with primary antibodies. The expression of PD-L1 and PD-L2 were detected using ChemMate EnVision 
Detection Kit with DAB substrate (Dako, Carpinteria, CA, USA) following the manufacturer's instruction with modification as described previously $[17,18]$.

The slides were blindly examined by two investigators. The slides were reviewed together to achieve consensus if the independent assessments did not agree. Tumor cells showing membranous staining for PD-L1 were considered as positive cells. We set the cut-off values at $1 \%, 5 \%, 10 \%$ and $50 \%$ for PD-L1 expression. PD-L2 IHC was scored as: 0 (no staining), $1+$ (cytoplasmic and/or weak membranous staining in $<50 \%$ of the tumor cells), $2+$ (weak to moderate membranous staining in $\geq 50 \%$ of the tumor cells),

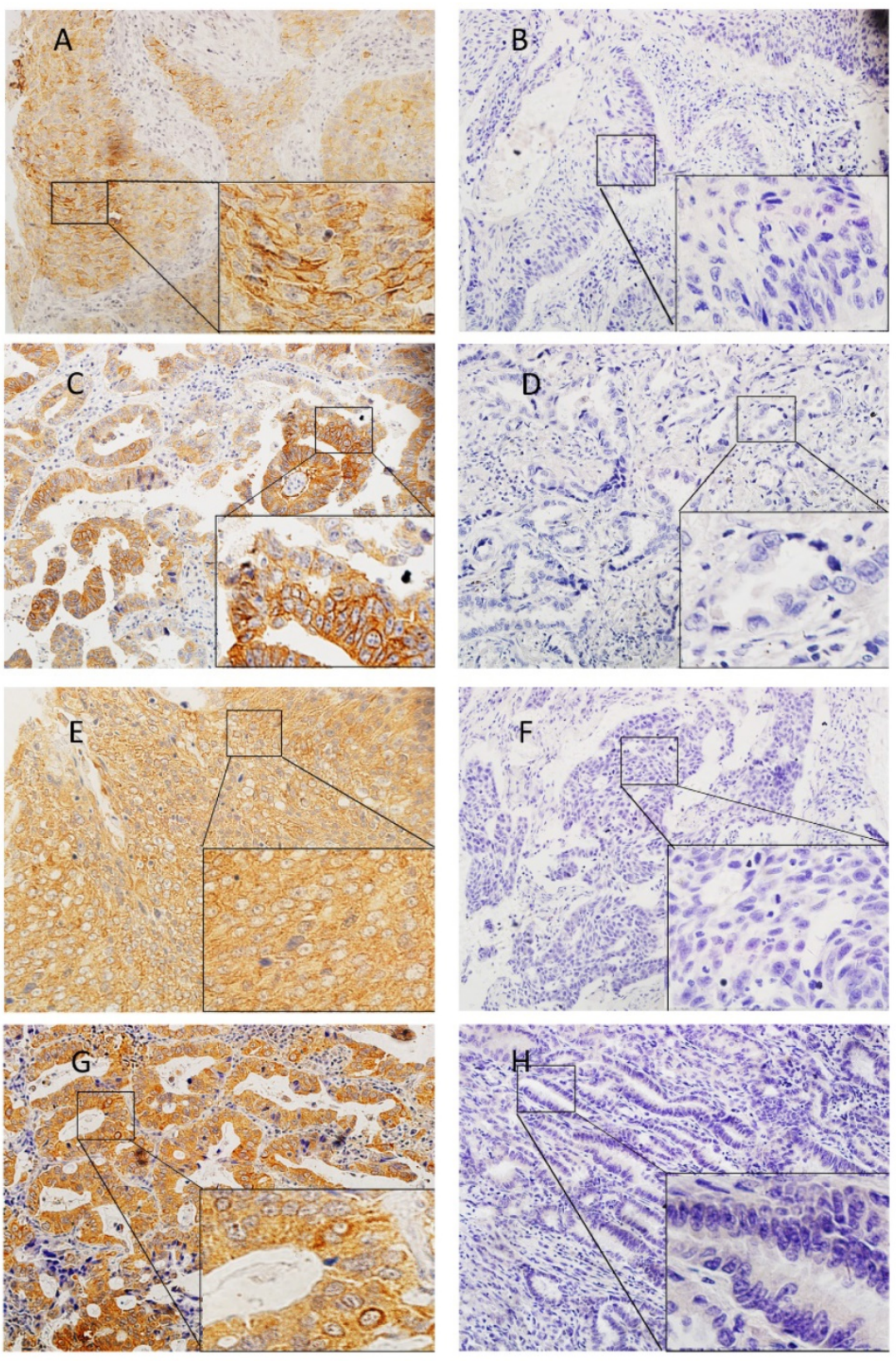

Figure 1. Expression of PD-L1 (A, B, C, D) and PD-L2 (E, F, G, H) in lung squamous cell carcinomas (A, $B, E, F)$ and adenocarcinomas (C, D, G, H). Representative images of positive expression (A, C, E, G). Representative images of negative expression (B, D, F, H) and $3+$ (strong membranous staining in $\geq 50 \%$ of the tumor cells). Specimens that scored as $2+$ or $3+$ were considered to be positive for PD-L2 expression (Figure 1).

\section{Statistical analysis}

SPSS 20.0 software (IBM Corporation, Armonch, NY, USA) was used for all statistical analyses. Univariate analyses of the relation between PD-L1 and PD-L2 and clinicopathologic parameters were performed using Chi-squared test or Fisher exact test, while multivariate analyses were performed by logistic regression analysis with the backward elimination method. Disease-free survival (DFS) was defined as the period from surgery to date of the recurrence, and overall survival (OS) was defined as the period from surgery to the date of the last follow-up or death. Cox proportional hazards regression analyses were performed to assess the hazard ratios for positive risk factors with the backward elimination method. Differences were considered statistically significant at a two-sided $\mathrm{p}$-value of $<0.05$.

\section{Results}

\section{Patient characteristics}

The clinicopathologic characteristics of the patients were summarized in Table 1. Among 364 patients, there were 228 (62.6\%) males and $136(37.4 \%)$ females with a median age of 59.5 years (range, 32-82 years), and 161 (44.2\%) patients were smokers with smoking index greater than or equal to 400 . At the time of diagnosis, $175(48.1 \%)$ patients were at stage I, $72(19.8 \%)$ were at stage II and $177(32.1 \%)$ were at stage IIIA. Thirty-seven patients (10.2\%) received pneumonectomy, 313 $(86.0 \%)$ received lobectomy, and 14 $(3.8 \%)$ underwent wedge resection. Of all surgically resected patients, 221 $(60.7 \%)$ patients received adjuvant treatment. The EGFR mutation rate was $17.6 \% \quad(64 / 364)$ among all NSCLC patients, 29.1\% (60/206) within adenocarcinoma (Table S1) and $2.5 \%(4 / 158)$ within squamous cell carcinoma cohorts (Table S2), respectively. 
Table 1. Clinicopathological Characteristics of All Patients.

\begin{tabular}{|c|c|c|}
\hline Variables & Number of patients & $\%$ \\
\hline \multicolumn{3}{|l|}{ Age (years) } \\
\hline Median (range) & $59(32-82)$ & \\
\hline$\leq 60$ & 188 & 51.6 \\
\hline$>60$ & 176 & 48.4 \\
\hline \multicolumn{3}{|l|}{ Gender } \\
\hline Male & 228 & 62.6 \\
\hline Female & 136 & 37.4 \\
\hline \multicolumn{3}{|c|}{ Smoking Index (SI) } \\
\hline SI $<400$ & 203 & 55.8 \\
\hline $\mathrm{SI} \geq 400$ & 161 & 44.2 \\
\hline \multicolumn{3}{|l|}{ Clinical stage } \\
\hline I & 175 & 48.1 \\
\hline II & 72 & 19.8 \\
\hline IIIA & 177 & 32.1 \\
\hline \multicolumn{3}{|l|}{ Tumor size } \\
\hline$\leq 3 \mathrm{~cm}$ & 167 & 45.9 \\
\hline$>3 \mathrm{~cm}$ & 197 & 54.1 \\
\hline \multicolumn{3}{|c|}{ Regional LN metastasis } \\
\hline No & 204 & 56.0 \\
\hline Yes & 160 & 44.0 \\
\hline \multicolumn{3}{|l|}{ Histology } \\
\hline $\mathrm{AD}$ & 206 & 56.6 \\
\hline SCC & 158 & 43.4 \\
\hline \multicolumn{3}{|c|}{ Operative approaches } \\
\hline Pneumonectomy & 37 & 10.2 \\
\hline Lobectomy & 313 & 86.0 \\
\hline Wedge resection & 14 & 3.8 \\
\hline \multicolumn{3}{|c|}{ Adjuvant treatment } \\
\hline No & 221 & 60.7 \\
\hline Yes & 143 & 39.3 \\
\hline \multicolumn{3}{|l|}{ EGFR mutation } \\
\hline No & 300 & 82.4 \\
\hline Yes & 64 & 17.6 \\
\hline \multicolumn{3}{|l|}{ NSE } \\
\hline$\leq 15.2 \mathrm{ng} / \mathrm{ml}$ & 249 & 68.4 \\
\hline$>15.2 \mathrm{ng} / \mathrm{ml}$ & 115 & 31.6 \\
\hline \multicolumn{3}{|l|}{ CEA } \\
\hline$\leq 5.0 \mathrm{ng} / \mathrm{ml}$ & 238 & 65.4 \\
\hline$>5.0 \mathrm{ng} / \mathrm{ml}$ & 126 & 34.6 \\
\hline \multicolumn{3}{|l|}{ Cyfra21-1 } \\
\hline$\leq 3.3 \mathrm{ng} / \mathrm{ml}$ & 195 & 53.6 \\
\hline$>3.3 \mathrm{ng} / \mathrm{ml}$ & 169 & 46.4 \\
\hline \multicolumn{3}{|l|}{ SCCA } \\
\hline$\leq 1.5 \mathrm{ng} / \mathrm{ml}$ & 283 & 77.7 \\
\hline$>1.5 \mathrm{ng} / \mathrm{ml}$ & 81 & 22.3 \\
\hline
\end{tabular}

\section{Association of PD-L1 and PD-L2 expression with clinicopathological features}

PD-L1 expression was present in 202 (55.5\%), 151 $(41.5 \%), 122(33.5 \%)$ and $81(22.3 \%)$ cases when using cutoff values of $1 \%, 5 \%, 10 \%$ and $50 \%$, respectively. PD-L2 was positively expressed in 179 (49.2\%) patients. In univariate analysis (Table 2), PD-L1 expression was significantly associated with moderate/heavy smoking history (SI $\geq 400$ ) for all cutoffs $(\mathrm{P}<0.001$ for $1 \%, 5 \%$ and $10 \%$ cutoffs, $\mathrm{p}=$ 0.005 for $50 \%$ cutoff). PD-L1 expression was more prevalent in male gender for $1 \%(\mathrm{P}=0.039)$ and $50 \%$ $(\mathrm{P}=0.170)$ cutoffs. Positive lymph node metastasis was associated with PD-L1 expression for $50 \%$ cutoff $(\mathrm{P}=0.017)$, but not for $1 \%, 5 \%$ or $10 \%$ cutoffs.
Squamous cell carcinoma had a nonsignificant trend towards higher PD-L1 expression compared with adenocarcinoma ( $\mathrm{P}=0.072$ for $10 \%$ cutoff, $\mathrm{P}=0.138$ for $50 \%$ cutoff). Interestingly, PD-L1 expression was closely correlated with serum SCCA level for almost all cutoffs $(\mathrm{P}=0.200$ for $1 \%$ cutoff, $\mathrm{P}=0.004$ for $5 \%$ cutoff, $\mathrm{P}=0.009$ for $10 \%$ cutoff and $\mathrm{P}=0.001$ for $50 \%$ cutoff). There was no correlation between PD-L1 expression and clinical stage or EGFR status. We also analyzed the relation between PD-L2 expression and the clinicopathological factors, but no statistically significant correlation was found (Table S3). Multivariate analysis revealed that moderate/heavy smoking history was associated with PD-L1 expression for all cutoffs, while SCCA level was associated with PD-L1 expression for all cutoffs except at $1 \%$ (Table S4).

Additional sub-analyses of different histological subtypes showed that PD-L1 expression correlated with moderate/heavy smoking history (SI $\geq 400$ ), larger tumor size, solid type adenocarcinoma, serum Cyfra21-1, and serum SCCA in adenocarcinoma for different cutoffs (Table S1). Conversely, a significant association was found between PD-L1 expression and female gender, moderate/heavy smoking history (SI $\geq$ 400), positive regional lymph node metastasis and wild type EGFR in squamous cell carcinoma for different cutoffs (Table S2).

\section{Prognostic significance of PD-LI and PD-L2 in NSCLC}

Median overall survival and disease-free survival of the total 364 patients were 38.0 months and 23.7 months, respectively. We assessed the association between PD-L1 expression and patient postoperative survival at four PD-L1 cutoff values. Univariate analysis showed that patients with high PD-L1 positivity shared significantly shorter DFS (hazard ratio [HR] 1.546, $\mathrm{P}=0.004$ ) and OS (HR 1.704, $\mathrm{P}=0.002)$ than those with low PD-L1 expression at a $50 \%$ cutoff value (Table 3) (Figure 2), but not at $1 \%$, $5 \%$ or $10 \%$ (Figure S1). Survival analysis was also used to assess the associations between PD-L2 expression and patient postoperative survival. Though no significantly association was found between PD-L2 expression and survival (either DFS or OS), patients with negative PD-L2 expression tended to have relatively longer DFS (HR 1.276, P = 0.063) (Table 3) (Figure S1). On the basis of these results, we adopted $50 \%$ cutoff value for further survival analyses. Univariate analysis showed besides $50 \%$ cutoff for PD-L1 expression, smoking history, clinical stage, regional lymph node metastasis, serum CEA, and serum SCCA were associated with significantly shorter DFS and OS. Additionally, patients who 
underwent adjuvant treatment and had elevated serum Cyfra21-1 levels shared a longer OS. To identify prognostic factors, we used multivariate analysis using the Cox regression model adjusted for all factors. PD-L1 positivity remained a predictor of DFS and OS at the 50\% cutoff value. Moreover, smoking history, advanced clinical stage, larger tumor size, elevated serum CEA and elevated serum SCCA remained independent risk factors for DFS, while smoking history, advanced clinical stage, no adjuvant therapy, elevated serum CEA level and elevated serum Cyfra21-1 level were poor prognostic indicators for OS (Table 3).

\section{Prognostic significance of PD-LI expression for $\mathbf{5 0} \%$ cutoff in subgroups}

To investigate PD-L1's clinical significance, patients were further divided into subgroups according to histology (adenocarcinoma vs. squamous cell carcinoma), serum SCCA level $(\leq 1.5$ $\mathrm{ng} / \mathrm{ml} \mathrm{vs}$. $>1.5 \mathrm{ng} / \mathrm{ml}$ ) and smoking history $(\mathrm{SI}<400$ vs. SI $\geq 400$ ).

Univariate analysis showed that PD-L1 expression at a 50\% cutoff was associated with significantly short DFS and OS only in patients with squamous cell carcinoma (DFS: HR 2.149, P $=0.001$; OS: HR 2.380, $\mathrm{P}<0.001$ ) but not adenocarcinoma. In patients with elevated SCCA, a significant association was found between PD-L1 expression and survival (DFS: HR 2.479, P = 0.001; OS: HR 2.145, P = 0.011), while no association was found between PD-L1 expression and survival in patients with low serum SCCA. Moreover, high PD-L1 expression was also associated with poor survival in patients with moderate/heavy smoking history (SI $\geq 400$, DFS: HR 1.704, P = 0.010; OS: HR 2.028, $\mathrm{P}=0.002$ ) (Table 4) (Figure 2).

Table 2. The association between PD-L1 expression and the clinicopathological factors.

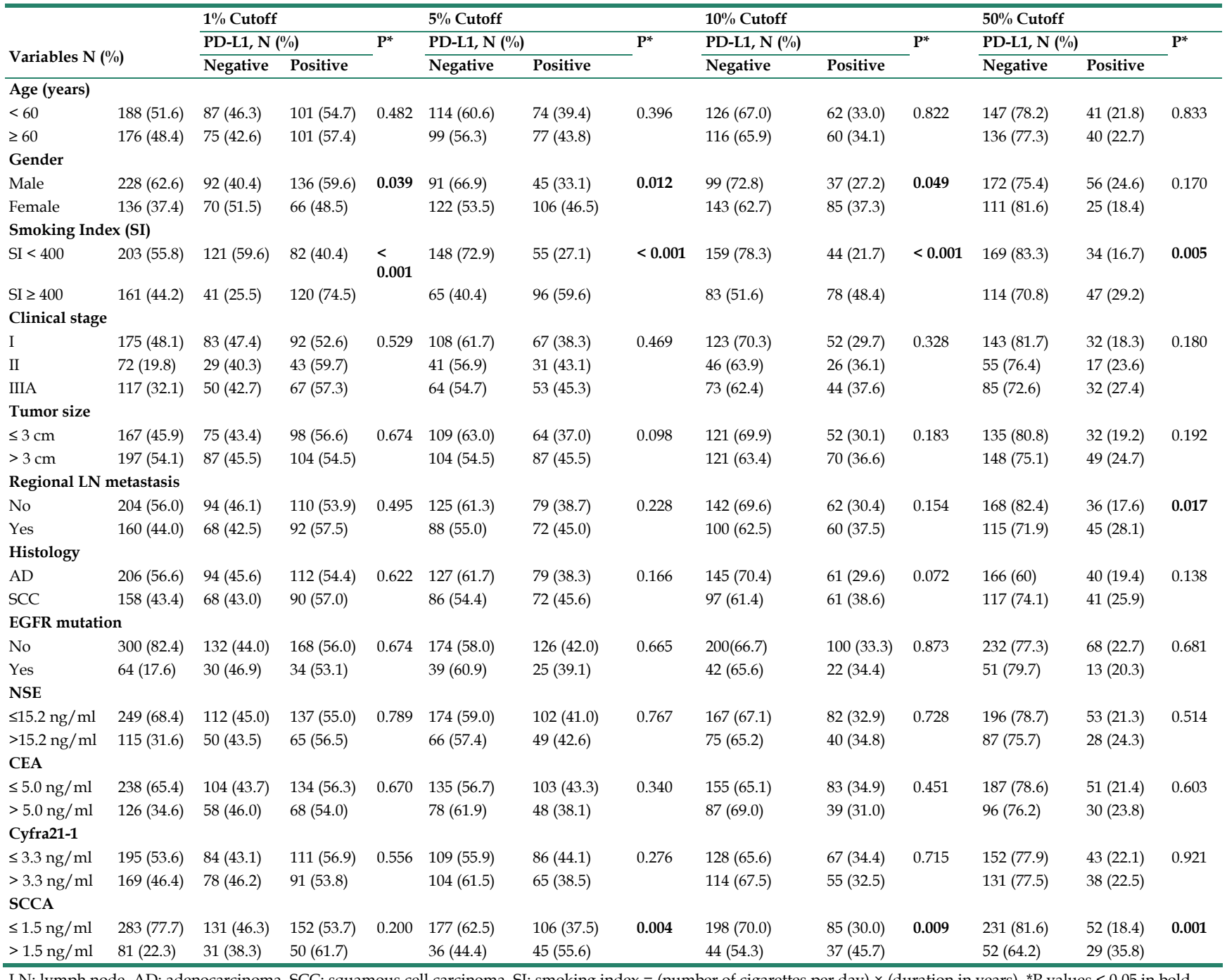

LN: lymph node. AD: adenocarcinoma. SCC: squamous cell carcinoma. SI: smoking index $=$ (number of cigarettes per day) $\times\left(\right.$ duration in years). ${ }^{*} \mathrm{P}$ values $<0.05$ in bold. 
Table 3. Univariate and multivariate analyses of DFS and OS in all patients using the $50 \%$ cutoff value.

\begin{tabular}{|c|c|c|c|c|c|c|c|c|c|c|}
\hline \multirow[b]{3}{*}{ Variables } & \multicolumn{5}{|l|}{ DFS } & \multicolumn{5}{|l|}{ OS } \\
\hline & \multicolumn{3}{|c|}{ Univariate Analysis } & \multicolumn{2}{|c|}{ Multivariate Analysis } & \multicolumn{3}{|c|}{ Univariate Analysis } & \multicolumn{2}{|c|}{ Multivariate Analysis } \\
\hline & $\begin{array}{l}\text { 5-year DFS } \\
\text { rate }(\%)\end{array}$ & HR $(95 \% \mathrm{CI})$ & $\mathrm{P}^{*}$ & $\mathrm{HR}(95 \% \mathrm{CI})$ & $\mathrm{P}^{*}$ & $\begin{array}{l}\text { 5-year OS rate } \\
(\%)\end{array}$ & HR $(95 \% \mathrm{CI})$ & $\mathrm{P}^{*}$ & $\mathrm{HR}(95 \% \mathrm{CI})$ & $\mathrm{P}^{*}$ \\
\hline \multicolumn{11}{|c|}{ All patients $(n=364)$} \\
\hline \multicolumn{11}{|l|}{ Age (years) } \\
\hline$<60$ & 38.3 & $1.108(0.857-1.433)$ & 0.434 & & & 54.3 & $1.205(0.899-1.616)$ & 0.212 & & \\
\hline$\geq 60$ & 34.1 & & & & & 49.4 & & & & \\
\hline \multicolumn{11}{|l|}{ Gender } \\
\hline Male & 36.8 & 1.005 (0.771-1.309) & 0.971 & & & 53.7 & $1.164(0.856-1.582)$ & 0.333 & & \\
\hline Female & 34.6 & & & & & 46.5 & & & & \\
\hline \multicolumn{11}{|c|}{ Smoking Index (SI) } \\
\hline SI $<400$ & 37.9 & 1.394 (1.076- 1.807) & 0.012 & $1.440(1.105-1.876)$ & 0.007 & 53.7 & $1.386(1.028-1.868)$ & 0.032 & $1.442(1.064-1.954)$ & 0.018 \\
\hline SI $\geq 400$ & 34.2 & & & & & 50.3 & & & & \\
\hline \multicolumn{11}{|l|}{ Clinical stage } \\
\hline I- II & 42.1 & $1.790(1.373-2.333)$ & $<0.001$ & 1.758 (1.331-2.322) & $<0.001$ & 59.5 & 1.899 (1.410- 2.558) & $<0.001$ & $2.132(1.559-2.914)$ & $<0.001$ \\
\hline IIIA & 23.1 & & & & & 36.9 & & & & \\
\hline \multicolumn{11}{|l|}{ Tumor size } \\
\hline$\leq 3 \mathrm{~cm}$ & 37.3 & $0.944(0.730-1.221)$ & 0.660 & $0.712(0.542-0.935)$ & 0.015 & 58.6 & $1.266(0.941-1.704)$ & 0.119 & & \\
\hline$>3 \mathrm{~cm}$ & 36.0 & & & & & 46.2 & & & & \\
\hline \multicolumn{11}{|c|}{ Regional LN metastasis } \\
\hline No & 42.6 & $1.586(1.226-2.052)$ & $<0.001$ & & & 61.3 & $1.729(1.288-2.321)$ & $<0.001$ & & \\
\hline Yes & 28.1 & & & & & 46.3 & & & & \\
\hline \multicolumn{11}{|l|}{ Histology } \\
\hline $\mathrm{AD}$ & 32.5 & $0.890(0.684-1.157)$ & 0.383 & & & 53.9 & $1.174(0.875-1.575)$ & 0.286 & & \\
\hline SCC & 41.1 & & & & & 49.4 & & & & \\
\hline \multicolumn{11}{|c|}{ Adjuvant treatment } \\
\hline No & 35.3 & 0.902 (0.693- 1.175) & 0.445 & & & 47.1 & $0.631(0.462-0.863)$ & 0.004 & $0.483(0.349-0.668)$ & $<0.001$ \\
\hline Yes & 37.8 & & & & & 60.1 & & & & \\
\hline \multicolumn{11}{|c|}{ EGFR mutation } \\
\hline No & 47.3 & $0.930(0.669-1.291)$ & 0.664 & & & 52.3 & $0.805(0.551-1.178)$ & 0.265 & & \\
\hline Yes & 32.8 & & & & & 50.0 & & & & \\
\hline \multicolumn{11}{|l|}{ NSE } \\
\hline$\leq 15.2 \mathrm{ng} / \mathrm{ml}$ & 36.5 & 0.997 (0.756- 1.314) & 0.981 & & & 55.4 & $1.271(0.939-1.720)$ & 0.121 & & \\
\hline$>15.2 \mathrm{ng} / \mathrm{ml}$ & 35.7 & & & & & 44.3 & & & & \\
\hline \multicolumn{11}{|l|}{ CEA } \\
\hline$\leq 5.0 \mathrm{ng} / \mathrm{ml}$ & 43.3 & 1.747 (1.346- 2.268) & $<0.001$ & $1.612(1.234-2.107)$ & $<0.001$ & 57.6 & $1.621(1.205-2.181)$ & 0.001 & $1.358(1.003-1.840)$ & 0.048 \\
\hline$>5.0 \mathrm{ng} / \mathrm{ml}$ & 23.0 & & & & & 41.3 & & & & \\
\hline Cyfra21-1 & & & & & & & & & & \\
\hline$\leq 3.3 \mathrm{ng} / \mathrm{ml}$ & 40.0 & $1.229(0.950-1.589)$ & 0.117 & & & 57.9 & $1.473(1.098-1.978)$ & 0.010 & $1.501(1.113-2.023)$ & 0.008 \\
\hline$>3.3 \mathrm{ng} / \mathrm{ml}$ & 32.0 & & & & & 45.6 & & & & \\
\hline SCCA & & & & & & & & & & \\
\hline$\leq 1.5 \mathrm{ng} / \mathrm{ml}$ & 37.8 & $1.352(1.00-1.828)$ & 0.050 & $1.382(1.015-1.881)$ & 0.040 & 54.8 & $1.480(1.057-2.073)$ & 0.022 & & \\
\hline$>1.5 \mathrm{ng} / \mathrm{ml}$ & 30.9 & & & & & 43.2 & & & & \\
\hline PD-L1 & & & & & & & & & & \\
\hline Negative & 38.9 & $1.546(1.150-2.079)$ & 0.004 & 1.411 (1.044-1.908) & 0.025 & 55.1 & $1.704(1.220-2.380)$ & 0.002 & 1.659 (1.179-2.333) & 0.004 \\
\hline Positive & 27.2 & & & & & 42.0 & & & & \\
\hline PD-L2 & & & & & & & & & & \\
\hline Negative & 39.5 & $1.276(0.987-1.651)$ & 0.063 & & & 53.5 & $1.148(0.856-1.539)$ & 0.355 & & \\
\hline Positive & 33.0 & & & & & 50.3 & & & & \\
\hline
\end{tabular}

Table 4. Univariate analysis by PD-L1 expression (PD-L1+ versus PD-L1-, 50\% Cutoff).

\begin{tabular}{|c|c|c|c|c|c|c|}
\hline & & & DFS & & OS & \\
\hline \multirow[t]{2}{*}{ variables } & & $\mathbf{N}$ & HR(95\% CI) & $\mathrm{p}^{*}$ & HR(95\% CI) & $\mathrm{p}^{*}$ \\
\hline & ALL & 364 & $1.546(1.150-2.079)$ & 0.004 & $1.704(1.220-2.380)$ & 0.002 \\
\hline \multirow[t]{3}{*}{ SI } & Stratified & 364 & $1.394(1.076-1.807)$ & 0.012 & $1.386(1.028-1.868)$ & 0.032 \\
\hline & $\mathrm{SI}<400$ & 203 & $1.259(0.801-1.979)$ & 0.318 & $1.257(0.745-2.122)$ & 0.391 \\
\hline & $\mathrm{SI} \geq 400$ & 161 & $1.704(1.137-2.554)$ & 0.010 & $2.028(1.286-3.199)$ & 0.002 \\
\hline \multirow[t]{3}{*}{ SCCA } & Stratified & 364 & $1.352(1.00-1.828)$ & 0.050 & $1.480(1.057-2.073)$ & 0.022 \\
\hline & $\leq 1.5 \mathrm{ng} / \mathrm{ml}$ & 283 & $1.225(0.846-1.773)$ & 0.283 & $1.415(0.926-2.162)$ & 0.108 \\
\hline & $>1.5 \mathrm{ng} / \mathrm{ml}$ & 81 & $2.479(1.430-4.296)$ & 0.001 & $2.145(1.191-3.864)$ & 0.011 \\
\hline \multirow[t]{3}{*}{ Histology } & Stratified & 364 & $0.890(.684-1.157)$ & 0.383 & $1.174(0.875-1.575)$ & 0.286 \\
\hline & $\mathrm{AD}$ & 206 & $1.141(0.758-1.718)$ & 0.526 & $1.241(0.759-2.030)$ & 0.390 \\
\hline & SCC & 158 & $2.149(1.382-3.340)$ & 0.001 & $2.380(1.487-3.810)$ & $<0.001$ \\
\hline
\end{tabular}

AD: adenocarcinoma. SCC: squamous cell carcinoma. SI: smoking index $=$ (number of cigarettes per day) $\times\left(\right.$ duration in years). ${ }^{*} \mathrm{P}$ values $<0.05$ in bold. 

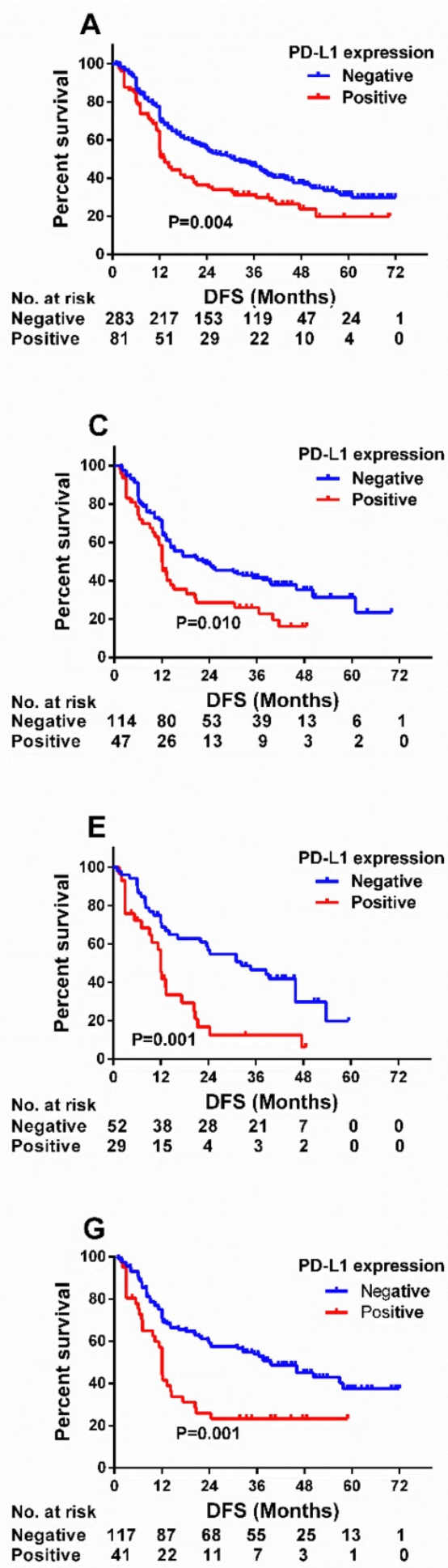
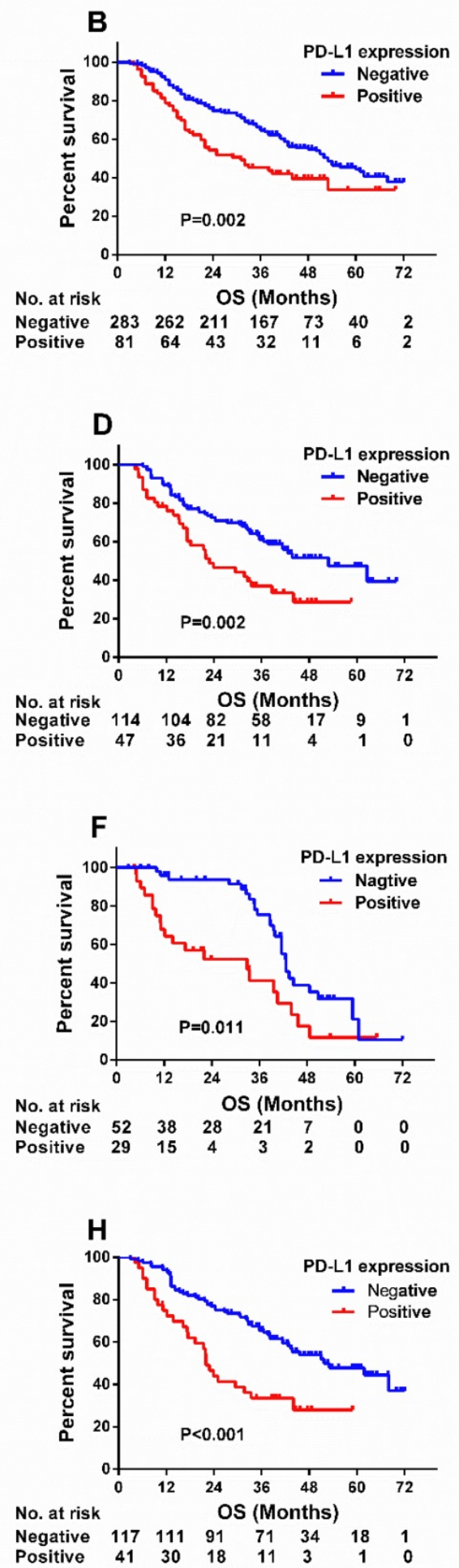

Figure 2. Kaplan-Meier survival curves of DFS (A) and OS (B) according to PD-L1 expression at a $50 \%$ cutoff value (negative vs. positive) in NSCLC patients. Kaplan-Meier survival curves of DFS (C, E, G) and OS (D, F, H) based on PD-Ll expression status (negative vs. positive) in patients with moderate/heavy-smoking (SI $\geq 400)(C, D)$, elevated serum SCCA level $($ SCCA $>1.5 \mathrm{ng} / \mathrm{ml})(E, F)$ and squamous cell carcinoma $(\mathrm{G}, \mathrm{H})$. Sl: smoking index $=($ number of cigarettes per day) $x$ (duration in years).

\section{Discussion}

The association between PD-L1/PD-L2 expression and clinicopathological characteristics, as well as the prognostic significance of PD-L1/ PD-L2 in NSCLC remain unclear. We performed this study to identify factors closely related to PD-L1 and PD-L2 expression, and to elucidate the role of PD ligands as predictive and prognostic markers of survival in NSCLC patients. 
We demonstrated a close relationship between PD-L1 expression, serum SCCA, and moderate/heavy smoking history. PD-L1 expression was also related to regional lymph node metastasis. High expression of PD-L1 was an independent unfavorable predictor of survival. Moreover, PD-L1 association with adverse prognosis differed by serum SCCA, moderate/strong smoking history and histological subtype. To our knowledge, this is the first study uncovers an intriguing correlation between PD-L1 expression and serum SCCA.

Recent studies have investigated PD-L1 protein expression in association with EGFR mutation [19-26]. However, some reports found that PD-L1 expression was higher in patients with EGFR mutations compared to those with wild-type EGFR [19, 25], while in other studies the reverse was true $[11,27]$. We found no significant correlation between PD-L1 expression and EGFR mutation status in NSCLC, which was consistent with other groups [20, 21]. These discrepancies may due to the differences in histological cell types and/or disease stages analyzed, different antibodies used, and/or different criteria employed for PD-L1 expression. Therefore, more studies are required to verify the association between PD-L1 expression and mutant EGFR status in NSCLC patients.

We found a significant association between regional lymph node metastasis and PD-L1 protein expression when using a $50 \%$ cutoff. This association was observed in both adenocarcinoma and squamous cell carcinomas when patients were stratified according to histology. Several previous studies identified a similar relationship between lymph node metastasis and PD-L1 expression (Table S5).

Additionally, our results showed that PD-L1 expression was higher in solid predominant tumors compared to other adenocarcinoma subtypes consistent with other reports [11, 27, 28]. The solid predominant subtype is associated with poorer prognoses compared with other subtypes [29].

Many recent studies have evaluated the prognostic value of PD-L1 expression in NSCLC [10-14, 20, 21, 27, 28, 30-32]. While we and others observed high PD-L1 expression associated with poorer prognosis $[10,12,27,32]$, some studies found either a favorable prognosis [20,21,30] or lack of association $[13,28]$. This discrepancy may be due to the different anti-PD-L1 antibodies used, different clinical stage of the whole cohorts, different distribution of histological subtype and different criteria of defining the positivity of PD-L1 expression. PD-L1 appeared to be a favorable prognostic factor only for stage I patients in one study [21], while another cohort included some advanced stage patients and used AQUA score to assess the PD-L1 expression, which was not commonly used [30]. Two other groups found no correlation between PD-L1 expression or prognosis unlike our results, even when using the same E1L3N PD-L1 antibody and cutoffs $[13,28]$. However, our findings of high PD-L1 expression associated with poor prognosis were consistent with two studies which used E1L3N for IHC $[14,32]$. PD-L1 positivity thresholds of $1 \%$ or $50 \%$ positive PD-L1 expression have been shown to be significantly prognostic $[10,32]$. While we tested $1 \%$, $5 \%, 10 \%$ and $50 \%$ PD-L1 thresholds, only the 50\% cutoff was prognostically significant. Our study showed that PD-L1 expression was significantly higher in patients with moderate/heavy smoking history and elevated serum SCCA levels and served as a prognostic marker in these subsets of patients. Because PD-L1 expression improves likelihood of NSCLC patient response to anti-PD-1/PD-L1 treatment [33], it is reasonable to hypothesize that moderate/heavy smoking history and high serum SCCA level may also have predictive value to this PD-1/PD-L1 blockade. In support of this, a correlation has been observed between smoking signature and the efficacy of anti-PD-1/PD-L1 inhibitors [34]. NSCLC patients with smoking history and smoking-associated lung squamous cell carcinoma had larger somatic mutation burdens [35, 36]. Studies based on the Cancer Genome Atlas project revealed recently that NSCLC had the greatest mutational burden per cell compared with other solid tumors, and had the significant sensitivity to anti-PD-1/PD-L1 antibody therapy as well [36, 37]. Somatic mutations could increase recognition of neoantigens, one important factor for successful immunotherapy. Though two recent large phase III studies that compared the efficacy of an anti-PD-1 antibody did not observe significantly different efficacies between squamous cell carcinoma and non-squamous cell carcinoma [6, 7], these histology types can exhibit different PD-L1 levels [10, 11, 38]. Clinical studies suggested that patients with higher PD-L1 expression could benefit more from anti-PD-1/PD-L1 inhibitors after a first-line therapy $[6,33]$. In our study, PD-L1 was significantly prognostic in patients with elevated serum SCCA. Although SCCA is believed to produce only by squamous epithelial cells, it is unclear whether alterations in serum SCCA levels actually represent an intratumor squamous-rich component in NSCLC. Taken together, this suggests that the prognostic value of PD-L1 exists not only in patients with squamous cell carcinoma, but also in adenocarcinoma patients with elevated serum SCCA. 
As to PD-L2 expression, we evaluated the association between PD-L2 expression and clinicopathologic and molecular parameters, including EGFR status, smoking history, age, sex, regional lymph node metastasis, clinical stage, tumor size as well as serum tumor markers, but no relationship was observed. Meanwhile, we found PD-L2 could not predict OS or PFS for NSCLC patients in our study, which is consistent with the studies of Jun et al. [39] and Kim et al. [24].

Our study has several limitations. This was a single institutional retrospective study and not a trial-based correlative study. We did not use the companion diagnostic antibodies used for the 3 corresponding FDA approved anti-PD-1/PD-L1 antibodies (pembrolizumab, atezolizumab and nivolumab). Dako/Agilent 28-8 assay was used for nivolumab, Dako/Agilent 22C3 assay for pembrolizumab, and the Ventana SP142 assay for atezolizumab. However, a recent study compared the concordance of 4 PD-L1 antibodies including 28-8, $22 \mathrm{C} 3, \mathrm{SP} 142$ and E1L3N, found that the assay using the SP142 antibody is an outlier while E1L3N, used in our study, together with 28-8 and 22C3 appeared to be interchangeable from an analytic perspective [40]. Additionally, our immunohistochemistry was performed on TMAs. TMAs may underrepresent tumor heterogeneity than the whole tissue sections, and TMAs are not used as standard diagnostic samples. Therefore, further studies of the association between PD-L1 expression and the clinicopathological characteristics as well as prognoses are warranted.

\section{Conclusion}

In conclusion, we observed that PD-L1 expression was correlated with moderate/heavy smoking history and elevated serum SCCA in NSCLC, and was an independently poor predictor of survival. We have shown that the prognostic value of PD-L1 expression differed by SCCA level, moderate/heavy smoking history and histology subtype.

\section{Abbreviations}

PD-1: Programmed cell death-1; NSCLC: non-small cell lung cancer; PD-L1: programmed death-1 ligand 1; SCCA: serum squamous cell carcinoma antigen; DFS: disease-free survival; OS: overall survival; CEA: carcinoembryonic antigen; NSE: neuron-specific enolase; Cyfra21-1: cytokeratin-19 fragments; EGFR: epidermal growth factor receptor; TNM: tumor-node-metastasis; TMA: Tissue microarrays; FFPE: formalin-fixed paraffin embedded; SI: smoking index; LN: lymph node; SCC: squamous cell carcinoma; AD: adenocarcinoma.

\section{Supplementary Material}

Supplementary figures and tables.

http://www.jcancer.org/v08p3251s1.pdf

\section{Acknowledgements}

This work was supported by grants from the National Natural Science Foundation of China (No. 81372517 and No. 81000899), the Tianjin Municipal Science and Technology Commission Key Application Research Projects (No. 11JCZDJC18900) for Richeng Jiang, and the Tianjin Municipal Science and Technology Commission Projects (No. 11JCYBJC11300 and No. 12ZCDZSY15600) for Kai Li. We are grateful to Dr. Douglas E. Linn (Brigham \& Women's Hospital, Boston, MA, USA) for critical reading of the manuscript.

\section{Competing Interests}

The authors have declared that no competing interest exists.

\section{References}

1. Dong H, Strome SE, Salomao DR, Tamura H, Hirano F, Flies DB, et al. Tumor-associated B7-H1 promotes T-cell apoptosis: a potential mechanism of immune evasion. Nature medicine. 2002; 8: 793-800.

2. Ishida Y, Agata Y, Shibahara K, Honjo T. Induced expression of PD-1, a novel member of the immunoglobulin gene superfamily, upon programmed cell death. The EMBO journal. 1992; 11: 3887-95.

3. Keir ME, Butte MJ, Freeman GJ, Sharpe AH. PD-1 and its ligands in tolerance and immunity. Annual review of immunology. 2008; 26: 677-704.

4. Sharpe AH, Freeman GJ. The B7-CD28 superfamily. Nature reviews Immunology. 2002; 2: 116-26.

5. Blank C, Gajewski TF, Mackensen A. Interaction of PD-L1 on tumor cells with PD-1 on tumor-specific $\mathrm{T}$ cells as a mechanism of immune evasion: implications for tumor immunotherapy. Cancer immunology, immunotherapy: CII. 2005; 54: 307-14.

6. Borghaei H, Paz-Ares L, Horn L, Spigel DR, Steins M, Ready NE, et al. Nivolumab versus Docetaxel in Advanced Nonsquamous Non-Small-Cell Lung Cancer. The New England journal of medicine. 2015; 373: 1627-39.

7. Brahmer J, Reckamp KL, Baas P, Crino L, Eberhardt WE, Poddubskaya E, et al. Nivolumab versus Docetaxel in Advanced Squamous-Cell Non-Small-Cell Lung Cancer. The New England journal of medicine. 2015; 373: 123-35.

8. Gettinger SN, Horn L, Gandhi L, Spigel DR, Antonia SJ, Rizvi NA, et al. Overall Survival and Long-Term Safety of Nivolumab (Anti-Programmed Death 1 Antibody, BMS-936558, ONO-4538) in Patients With Previously Treated Advanced Non-Small-Cell Lung Cancer. Journal of clinical oncology: official journal of the American Society of Clinical Oncology. 2015; 33: 2004-12.

9. Inoue Y, Yoshimura K, Mori K, Kurabe N, Kahyo T, Mori H, et al. Clinical significance of PD-L1 and PD-L2 copy number gains in non-small-cell lung cancer. Oncotarget. 2016; 7: 32113-28.

10. Sun J-M, Zhou W, Choi Y-L, Choi S-J, Kim SE, Wang Z, et al. Prognostic Significance of PD-L1 in Patients with Non-Small Cell Lung Cancer: A Large Cohort Study of Surgically Resected Cases. Journal of Thoracic Oncology. 2016; 11: 1003-11.

11. Takada K, Toyokawa G, Okamoto T, Shimokawa M, Kozuma Y, Matsubara T, et al. A Comprehensive Analysis of Programmed Cell Death Ligand-1 Expression with the Clone SP142 Antibody in Non-Small-Cell Lung Cancer Patients. Clinical lung cancer. 2017.

12. Okita R, Maeda A, Shimizu K, Nojima Y, Saisho S, Nakata M. PD-L1 overexpression is partially regulated by EGFR/HER2 signaling and associated with poor prognosis in patients with non-small-cell lung cancer. Cancer Immunology, Immunotherapy. 2017.

13. Ameratunga $M$, Asadi $K$, Lin $X$, Walkiewicz M, Murone $C$, Knight S, et al PD-L1 and Tumor Infiltrating Lymphocytes as Prognostic Markers in Resected NSCLC. PloS one. 2016; 11: e0153954.

14. Shimoji M, Shimizu S, Sato $K$, Suda K, Kobayashi $Y$, Tomizawa K, et al. Clinical and pathologic features of lung cancer expressing programmed cell death ligand 1 (PD-L1). Lung cancer. 2016; 98: 69-75.

15. Jiang $\mathrm{R}$, Wang $\mathrm{X}$, Li K. Predictive and prognostic value of preoperative serum tumor markers is EGFR mutation-specific in resectable non-small-cell lung cancer. Oncotarget. 2016; 7: 26823-36. 
16. Zhi Q, Wang Y, Wang X, Yue D, Li K, Jiang R. Predictive and prognostic value of preoperative serum tumor markers in resectable adenosqamous lung carcinoma. Oncotarget. 2016; 7: 64798-809.

17. Jiang R, Wang X, Jin Z, Li K. Association of Nuclear PIM1 Expression with Lymph Node Metastasis and Poor Prognosis in Patients with Lung Adenocarcinoma and Squamous Cell Carcinoma. Journal of Cancer. 2016; 7: 324-34.

18. Jiang R, Jin Z, Liu Z, Sun L, Wang L, Li K. Correlation of activated STAT3 expression with clinicopathologic features in lung adenocarcinoma and squamous cell carcinoma. Molecular diagnosis \& therapy. 2011; 15: 347-52.

19. Azuma K, Ota K, Kawahara A, Hattori S, Iwama E, Harada T, et al Association of PD-L1 overexpression with activating EGFR mutations in surgically resected nonsmall-cell lung cancer. Annals of oncology: official journal of the European Society for Medical Oncology. 2014; 25: 1935-40.

20. Cooper WA, Tran T, Vilain RE, Madore J, Selinger CI, Kohonen-Corish M, et al. PD-L1 expression is a favorable prognostic factor in early stage non-small cell carcinoma. Lung cancer. 2015; 89: 181-8.

21. Yang CY, Lin MW, Chang YL, Wu CT, Yang PC. Programmed cell death-ligand 1 expression in surgically resected stage I pulmonary adenocarcinoma and its correlation with driver mutations and clinical outcomes. European journal of cancer (Oxford, England: 1990). 2014; 50: 1361-9.

22. Tang Y, Fang W, Zhang Y, Hong S, Kang S, Yan Y, et al. The association between PD-L1 and EGFR status and the prognostic value of PD-L1 in advanced non-small cell lung cancer patients treated with EGFR-TKIs. Oncotarget. 2015; 6: 14209-19.

23. Mu CY, Huang JA, Chen Y, Chen C, Zhang XG. High expression of PD-L1 in lung cancer may contribute to poor prognosis and tumor cells immune escape through suppressing tumor infiltrating dendritic cells maturation. Medical oncology. 2011; 28: 682-8

24. Kim MY, Koh J, Kim S, Go H, Jeon YK, Chung DH. Clinicopathological analysis of PD-L1 and PD-L2 expression in pulmonary squamous cell carcinoma: Comparison with tumor-infiltrating $\mathrm{T}$ cells and the status of oncogenic drivers. Lung cancer. 2015; 88: 24-33.

25. D'Incecco A, Andreozzi M, Ludovini V, Rossi E, Capodanno A, Landi L, et al. PD-1 and PD-L1 expression in molecularly selected non-small-cell lung cancer patients. British journal of cancer. 2015; 112: 95-102

26. Wu S, Shi X, Sun J, Liu Y, Luo Y, Liang Z, et al. The significance of programmed cell death ligand 1 expression in resected lung adenocarcinoma. Oncotarget. 2017; 8: 16421-9.

27. Takada K, Okamoto T, Shoji F, Shimokawa M, Akamine T, Takamori S, et al. Clinical Significance of PD-L1 Protein Expression in Surgically Resected Primary Lung Adenocarcinoma. Journal of thoracic oncology: official publication of the International Association for the Study of Lung Cancer. 2016; 11: 1879-90.

28. Uruga H, Bozkurtlar E, Huynh TG, Muzikansky A, Goto Y, Gomez-Caraballo M, et al. Programmed Cell Death Ligand (PD-L1) Expression in Stage II and III Lung Adenocarcinomas and Nodal Metastases. Journal of thoracic oncology: official publication of the International Association for the Study of Lung Cancer. 2017; 12: 458-66.

29. Yoshizawa A, Motoi N, Riely GJ, Sima CS, Gerald WL, Kris MG, et al. Impact of proposed IASLC/ATS/ERS classification of lung adenocarcinoma: prognostic subgroups and implications for further revision of staging based on analysis of 514 stage I cases. Modern Pathology. 2011; 24: 653-64.

30. Velcheti V, Schalper KA, Carvajal DE, Anagnostou VK, Syrigos KN, Sznol M, et al. Programmed death ligand-1 expression in non-small cell lung cancer. Laboratory investigation; a journal of technical methods and pathology. 2014; 94: 107-16.

31. Takada K, Okamoto T, Toyokawa G, Kozuma Y, Matsubara T, Haratake N, et al. The expression of PD-L1 protein as a prognostic factor in lung squamous cell carcinoma. Lung cancer. 2017; 104: 7-15.

32. Huynh TG, Morales-Oyarvide V, Campo MJ, Gainor JF, Bozkurtlar E, Uruga $\mathrm{H}$, et al. Programmed Cell Death Ligand 1 Expression in Resected Lung Adenocarcinomas: Association with Immune Microenvironment. Journal of Thoracic Oncology. 2016; 11: 1869-78.

33. Garon EB, Rizvi NA, Hui R, Leighl N, Balmanoukian AS, Eder JP, et al. Pembrolizumab for the treatment of non-small-cell lung cancer. The New England journal of medicine. 2015; 372: 2018-28.

34. Rizvi NA, Hellmann MD, Snyder A, Kvistborg P, Makarov V, Havel JJ, et al. Cancer immunology. Mutational landscape determines sensitivity to PD-1 blockade in non-small cell lung cancer. Science (New York, NY). 2015; 348: 124-8.

35. Vogelstein B, Papadopoulos N, Velculescu VE, Zhou S, Diaz LA, Jr., Kinzler KW. Cancer genome landscapes. Science (New York, NY). 2013; 339: 1546-58.

36. Alexandrov LB, Nik-Zainal S, Wedge DC, Aparicio SA, Behjati S, Biankin AV, et al. Signatures of mutational processes in human cancer. Nature. 2013; 500: 415-21.

37. Champiat S, Ferte C, Lebel-Binay S, Eggermont A, Soria JC. Exomics and immunogenics: Bridging mutational load and immune checkpoints efficacy. Oncoimmunology. 2014; 3: e27817.

38. Xu C, Fillmore CM, Koyama S, Wu H, Zhao Y, Chen Z, et al. Loss of Lkb1 and Pten leads to lung squamous cell carcinoma with elevated PD-L1 expression. Cancer cell. 2014; 25: 590-604.

39. Konishi J, Yamazaki K, Azuma M, Kinoshita I, Dosaka-Akita H, Nishimura M. B7-H1 expression on non-small cell lung cancer cells and its relationship with tumor-infiltrating lymphocytes and their PD-1 expression. Clinical cancer research: an official journal of the American Association for Cancer Research. 2004; 10: 5094-100.

40. Rimm DL, Han G, Taube JM, Yi ES, Bridge JA, Flieder DB, et al. A Prospective, Multi-institutional, Pathologist-Based Assessment of 4 Immunohistochemistry Assays for PD-L1 Expression in Non-Small Cell Lung Cancer. JAMA oncology. 2017. 